\title{
Assessment of pubovisceral muscle defects and levator hiatal dimensions in women with faecal incontinence after vaginal delivery: is there a correlation with severity of symptoms?
}

\author{
S. M. Murad-Regadas*†, G. O. da S. Fernandes*, F. S. P. Regadas*, L. V. Rodrigues*, J. de J. R. \\ Pereira*, I. D. Dealcanfreitas* and F. S. P. Regadas Filho* \\ *Department of Surgery, School of Medicine of the Federal University of Ceará, Fortaleza, Ceará, Brazil and †Department of Anorectal Physiology and \\ Pelvic Floor Dysfunctions, Clinical Hospital, Federal University of Ceará, Fortaleza, Ceará, Brazil
}

Received 22 March 2014; accepted 4 June 2014; Accepted Article online 8 August 2014

\begin{abstract}
Aim We assessed pubovisceral muscle (PVM) defects, levator hiatal dimensions and anal sphincter defects using three-dimensional (3D) endovaginal and anorectal ultrasonography in women with previous vaginal delivery and faecal incontinence to determine the relationship between anatomic/functional findings and severity of faecal incontinence symptoms.
\end{abstract}

Method This was a prospective, observational study including 52 women with faecal incontinence symptoms who had undergone vaginal delivery. Asymptomatic nulliparous women $(n=17)$ served as controls to provide reference values for pelvic floor measurements. All participants underwent 3D endovaginal and anorectal ultrasonography. We used an ultrasound score to identify and quantify the extent of PVM defects and sphincter damage and to measure levator hiatal dimensions. Incontinence was assessed using the Cleveland Clinic Florida Incontinence Scoring System.

Results Defects of the PVM were identified with 3D endovaginal ultrasonography in $27 \%$ of women with faecal incontinence who had undergone vaginal delivery. The incontinence score and the ultrasound score were significantly higher in women with a PVM defect. A significant, positive correlation was found between the incontinence score and the ultrasound score. The levator hiatal dimensions were significantly greater, and the

\section{Introduction}

Vaginal delivery affects the anatomy and function of the levator ani muscle and the dimensions of the urogenital hiatus, and may result in macroscopic damage or

Correspondence to: Sthela M. Murad-Regadas, PhD, Department of Surgery, School of Medicine, Clinical Hospital, Federal University of Ceará, Av Pontes Vieira, 255I, Fortaleza, Ceará, 60I30-24I Brazil.

E-mail: smregadas@hospitalsaocarlos.com.br positions of the anorectal junction and bladder neck were lower, in women who had undergone vaginal delivery than in nulliparous women.

Conclusion As determined by the 3D ultrasound score, severity of incontinence is related to the extent of damage of the PVM, as well as of the anal sphincters. Additionally, vaginal delivery results in enlargement of the levator hiatus and a lower position of the anorectal junction and bladder neck compared with nulliparous women.

Keywords Pelvic floor, physiology, faecal incontinence, ultrasound, anatomy

\section{What does this paper add to the literature?}

We have proposed an ultrasound score to quantify the extent of pubovisceral muscle (PVM) and sphincter defects using three-dimensional (3D) endovaginal and anorectal ultrasonography in women. We used this score to determine the relationship between extent of damage and faecal incontinence symptoms. Severity of incontinence was related to the presence and extent of PVM defects as well as anal sphincter defects. Although no conclusions regarding causality can be drawn from a correlational study, it may be important to consider potential damage to the PVM in addition to sphincter defects when evaluating women with incontinence after vaginal delivery.

excessive distention during delivery $[1-4]$. The prevalence of anal sphincter injury after vaginal delivery has been reported to range from $11 \%$ to $35 \%$, as identified by ultrasonography, and the probability of faecal incontinence is higher [5-9].

The levator ani muscle has a recognized role in supporting the pelvic floor. The nomenclature in the literature regarding the levator ani varies. As proposed by DeLancey et al. [10], we use the term 'pubovisceral 
muscle' (PVM) as synonymous with the term 'pubococcygeus/puborectalis' because the two components cannot be distinguished on imaging. Anatomic alteration of the insertion of the PVM has been clearly demonstrated after vaginal childbirth. The most common form of major levator trauma appears to be an avulsion injury at the insertion of the muscle on the pubic ramus, which has been found on MRI and ultrasonography [1$3,11,12]$ in $15-55 \%$ of parous women after vaginal delivery, and which is associated with pelvic organ prolapse and ballooning of the hiatal dimensions $[4,13,14]$.

Few studies have examined the relationship between PVM damage and faecal incontinence $[15,16]$. Complete evaluation of the anal sphincter and the PVM is needed to identify lesions accurately and to determine potential correlations with symptoms. As an alternative to MRI and conventional ultrasonography, threedimensional (3D) endovaginal and anorectal ultrasonography offers a means of visualizing the morphology and function of the pelvic floor in multiple planes and at high resolution [17]. Thus, the aim of this study was to use 3D endovaginal and anorectal ultrasonography to assess PVM defects and levator hiatal dimensions in incontinent women with previous vaginal delivery and to correlate the anatomic and functional findings with the severity of faecal incontinence.

\section{Method}

\section{Patients}

The clinical protocol was approved by the Research Ethics Committee of the Walter Cantídio University Hospital, and all patients gave written informed consent. Eligible patients were consecutive women with previous vaginal delivery treated for faecal incontinence symptoms between January 2012 and June 2013 at the Walter Cantídio University Hospital of the Federal University of Ceara, Brazil. The patients were divided into groups according to the presence or absence of a PVM defect. The patients were also assessed for urinary incontinence, including the following: the presence of any involuntary leakage of urine; leakage on effort, exertion, sneezing or coughing; and/or leaking or loss of urine associated with an urge to urinate [18]. Patients with inflammatory bowel disease, human immunodeficiency virus (HIV) infection, obesity, diabetes or neurological disorders were excluded, as were patients with a history of previous colorectal, anorectal or gynaecological surgery.

\section{Control group}

A control group comprising 17 asymptomatic nulliparous women without previous surgery was recruited through the colorectal and gynaecological outpatient clinics of the Walter Cantídio University Hospital. Exclusion criteria were the same as for the patient group, except that patients with symptoms of stress and urge urinary incontinence were also excluded.

\section{Assessment}

\section{Clinical}

All assessments were performed at one clinic visit. Faecal incontinence was assessed using the Cleveland Clinic Florida Incontinence Scoring System [19]. This incontinence scale addresses the leakage of flatus, liquid and solid stool, need for pads, and lifestyle alteration at varying frequencies, and the extent to which the patient's life is altered.

\section{Three-dimensional ultrasonography}

All participants, including incontinent patients and the control group, underwent 3D endovaginal and anorectal ultrasonography. Administration of a rectal enema was completed $2 \mathrm{~h}$ before the scan. A $3 \mathrm{D}$ ultrasound endoprobe (Pro-Focus 2052; 9-16 MHz; focal distance 2.8-6.2 cm; BK Medical, Herlev, Denmark) was used. Images up to $6 \mathrm{~cm}$ long were captured along the proximal-distal axis for up to $55 \mathrm{~s}$ by moving two crystals (axial and longitudinal) on the extremity of the transducer automatically, without moving the probe. The examination involved a series of transaxial microsections up to $0.20 \mathrm{~mm}$ thick, producing a high-resolution digitalized volumetric image. It was performed by a single colorectal surgeon (SMMR) with experience in $3 \mathrm{D}$ ultrasonography. Volume was displayed as a $3 \mathrm{D}$ cube image and was recorded and analysed in multiple planes.

\section{Technique}

\section{Endovaginal approach}

Patients were placed in the dorsal lithotomy position. A transducer at $12 \mathrm{mHz}$ was placed in the vagina in the neutral position above the bladder neck. The ultrasound examination identified the PVM at the point at which the inferior branches of the pubis bones join at the symphysis pubis as a hyperechoic sling lying posteriorly to the anorectal junction and anal canal and attaching to the pubic bone. A PVM defect was defined as the detachment (discontinuity) of the PVM from its insertion on the pubic rami. This was divided into complete detachment, involving the total muscle (i.e. the whole length of the muscle was compromised), or partial detachment, which was either unilateral or bilateral. 
The volume of the defect was measured from the edge of the muscle remnant to either side of the pelvic side wall representing the inferior pubic ramus. The following biometric indices of the levator hiatus were measured: anteroposterior diameter (the distance between the inferior margin of the symphysis pubis and the inner margin of the PVM), laterolateral diameter (the distance between the inner margins of the lateral branches of the PVM at the level of their attachment to the pubic bone) and area [17]. Further calculations included the position of the anorectal junction (as measured from the anorectal junction to the lowest margin of the symphysis pubis) and the position of the bladder neck (as measured from the bladder neck to the lowest margin of the symphysis pubis). All measurements were recorded and compared at rest and during a Valsalva manoeuvre.

\section{Anorectal approach}

Patients were placed in the left lateral position. After digital rectal examination, the endoprobe was introduced as far as the upper anal canal. The ultrasound examination identified the sphincter defect and whether it involved both the external anal sphincter (EAS) and the internal anal sphincter (IAS), or the EAS alone. The defect was recorded as being partial or total.

\section{Evaluation}

The extent of the defect identified by ultrasound examination was given by a score ranging from 0 to 8 , based on the amount of involvement (partial or whole length) of the EAS and the IAS, and whether the damage was unilateral or bilateral (Table 1; Fig. 1). For example, a patient with a defect of the whole EAS combined with a defect of the whole IAS but no PVM defect would have a score of 4 , whereas a patient with a bilateral defect of the whole PVM in addition to the combined EAS/IAS defect would have a score of 8 (a defect of the whole PVM on one side increases the score by 2 points, and a defect of the entire second side increases the score by a further 2 points).

Table I Three-dimensional endovaginal and anorectal ultrasonography scoring system for evaluating the extent of anal sphincter and pubovisceral muscle defects.

\begin{tabular}{llll}
\hline & \multicolumn{2}{l}{ Score } & \\
\cline { 2 - 4 } Defect & 0 & 1 & 2 \\
\hline External anal sphincter & None & Partial & $\begin{array}{l}\text { Total } \\
\text { Internal anal sphincter }\end{array}$ \\
$\begin{array}{llll}\text { Pubovisceral muscle } \\
\text { Unilateral (left side) }\end{array}$ & None & Partial & Total \\
Unilateral (right side) & None & Partial & Total \\
& & Partial & Total \\
\hline
\end{tabular}

To determine interobserver variability of the 3D transvaginal-approach measurements, all images (entire 3D cubes) were numbered randomly and were then measured independently by two surgeons (SMMR and GOSF) blinded to the findings of the original measurements. Interobserver agreement was assessed in a sample of 20 study participants that included both incontinent patients and controls.

\section{Statistical analysis}

The groups were compared with regard to the incontinence and ultrasound scores and 3D transvaginal and anorectal measurements. The incontinent groups (with or without a PVM defect) were also compared with the control group. Differences between groups were assessed using the Student's $t$-test and one-way ANOVA for continuous data. The $\chi^{2}$ test was used to compare the groups with regard to age distribution, number of vaginal deliveries and the presence or absence of urinary incontinence symptoms. The level of statistical significance was set at $P<0.05$. The relationships between incontinence scores and ultrasound scores or levator hiatal area were evaluated by calculating Spearman rank correlation coefficients $(\rho)$. In patients with a PVM defect, the correlation between the volume of the PVM defect and levator hiatal area was also calculated using Spearman rank correlation coefficients $(\rho)$.

Interobserver agreement was assessed by calculating intraclass correlation coefficients with 95\% CI. The strength of agreement was interpreted according to the Altman classification system $(<0.20$, poor; $0.21-0.40$, fair; $0.41-0.60$, moderate; $0.61-0.80$, good; and $0.81-$ 1.00 , very good) [20]. Data were analysed using spss software (version 14.0 for Windows; IBM-SPSS, Chicago, Illinois, USA).

\section{Results}

\section{Patient characteristics}

Sixty-nine women were included in the study: 52 patients with symptoms of faecal incontinence who had undergone at least one vaginal delivery; and 17 asymptomatic nulliparous volunteers, who served as controls. Of the 52 patients, $14(27 \%)$ had a PVM defect and 38 $(73 \%)$ had an intact PVM. In the 14 patients with a PVM defect, the mean age \pm SD was $61 \pm 9.9$ (range: 34-75) years, the median number of vaginal deliveries was 2 (range: $1-6$ ) and six (43\%) patients complained of urinary incontinence. In the 38 patients with an intact PVM, the mean age \pm SD was $61 \pm 17.3$ (range: 17-87) years, the median number of vaginal deliveries 

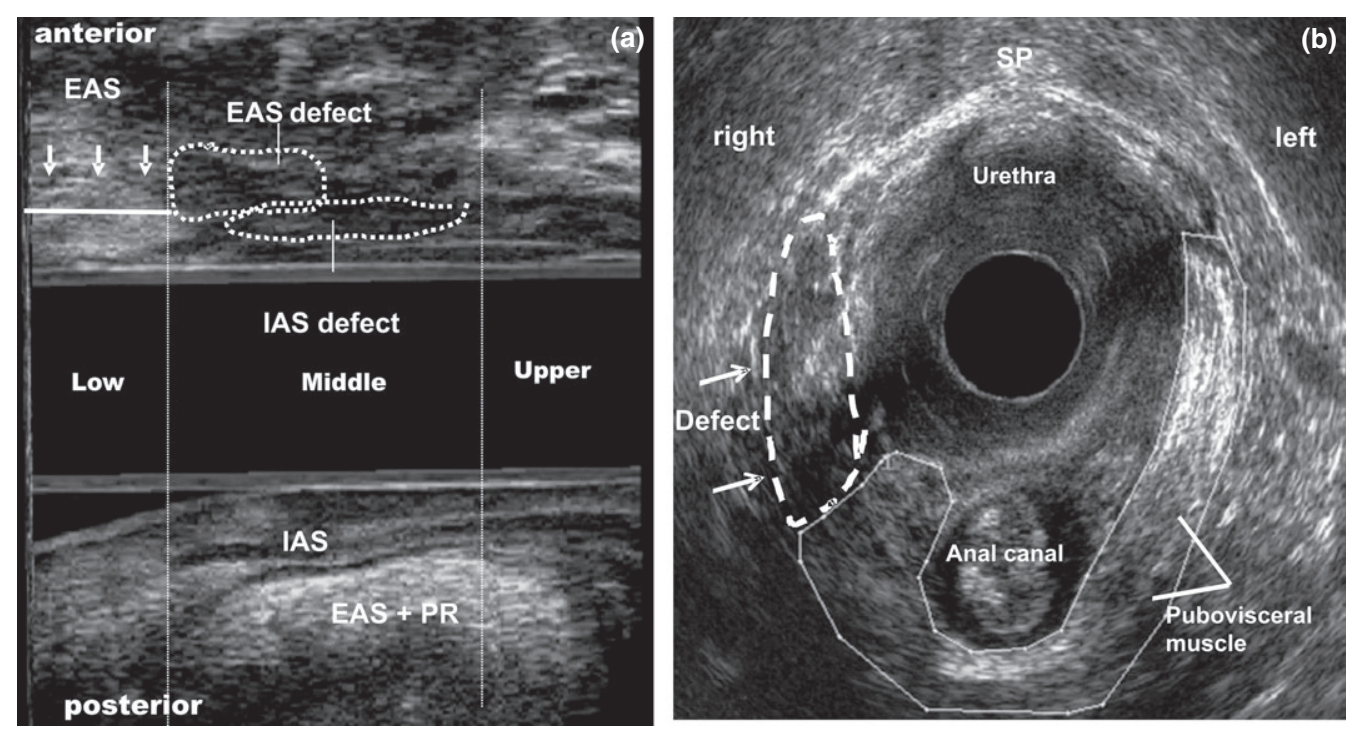

Figure I Combined partial external anal sphincter (EAS) and internal anal sphincter (IAS) defects and unilateral pubovisceral defect after vaginal delivery. (a) Three-dimensional (3D) anorectal ultrasonography. Measurements of the length of the residual EAS (arrows) and IAS (sagittal plane) are shown. (b) 3D endovaginal ultrasonography. Pubovisceral muscle defect (right side) (arrows) (axial plane). EAS+PR, external anal sphincter plus puborectalis muscle; SP, symphysis pubis.

per patient was 2 (range: $1-5)$ and $14(37 \%)$ patients complained of urinary incontinence. No significant differences in age, number of vaginal deliveries or presence of urinary incontinence were observed between the groups. The mean age \pm SD of the control group was $28 \pm 7.2$ (range: $18-44$ ) years.

\section{Incontinence scores and 3D ultrasonography}

Both the faecal incontinence score and the ultrasound score were significantly higher in patients with a PVM defect than in those with an intact PVM (Table 2; Fig. 2). In the 14 patients with a PVM defect, the defect was unilateral in $10(71 \%)$, including eight patients with partial and two with total detachment, and complete detachment involving the entire muscle was found in four $(29 \%)$ patients. Six $(43 \%)$ of the 14 patients had an intact anal sphincter, two (14\%) had an EAS defect and six $(43 \%)$ had a combined EAS/IAS defect. Of the 38 patients with an intact PVM, $17(45 \%)$ had an intact anal sphincter, $16(42 \%)$ had an EAS defect and five (13\%) had a combined EAS/IAS defect.

The laterolateral diameter and the area of the levator hiatus were significantly larger at rest and during a Valsalva manoeuvre in patients with a PVM defect than in those with an intact PVM (Table 3; Fig. 3). During Valsalva the hiatal area increased by $15 \%$ in patients with a PVM defect and by $8 \%$ in women with an intact PVM, but there was no increase in the nulliparous volunteers $(P=0.03)$. The biometric indices of the levator hiatus (anteroposterior and laterolateral diameter and area) were significantly larger, and the anorectal junction position and bladder neck position were significantly lower, in patients who underwent a vaginal delivery compared with the nulliparous volunteers (Table 3; Fig. 4).

Table 2 Incontinence and three-dimensional (3D) ultrasound scores in 52 incontinent women with previous vaginal delivery, with $(n=14)$ and without $(n=38)$ a pubovisceral muscle defect.

\begin{tabular}{|c|c|c|c|c|c|c|c|}
\hline \multirow[b]{3}{*}{ Score } & \multicolumn{6}{|c|}{ Pubovisceral muscle } & \multirow[b]{3}{*}{$P$} \\
\hline & \multicolumn{3}{|c|}{ Defect $(n=14)$} & \multicolumn{3}{|c|}{ Intact $(n=38)$} & \\
\hline & Mean & SD & Range & Mean & SD & Range & \\
\hline Incontinence score & 7.9 & 3.6 & $3-16$ & 4.2 & 1.7 & $2-8$ & 0.001 \\
\hline 3D ultrasound score* & 3 & 2.3 & $1-8$ & 0.7 & 0.7 & $0-2$ & 0.001 \\
\hline
\end{tabular}

*Scores ranged from 0 to 8 , with a score of 8 representing the greatest amount of involvement. 

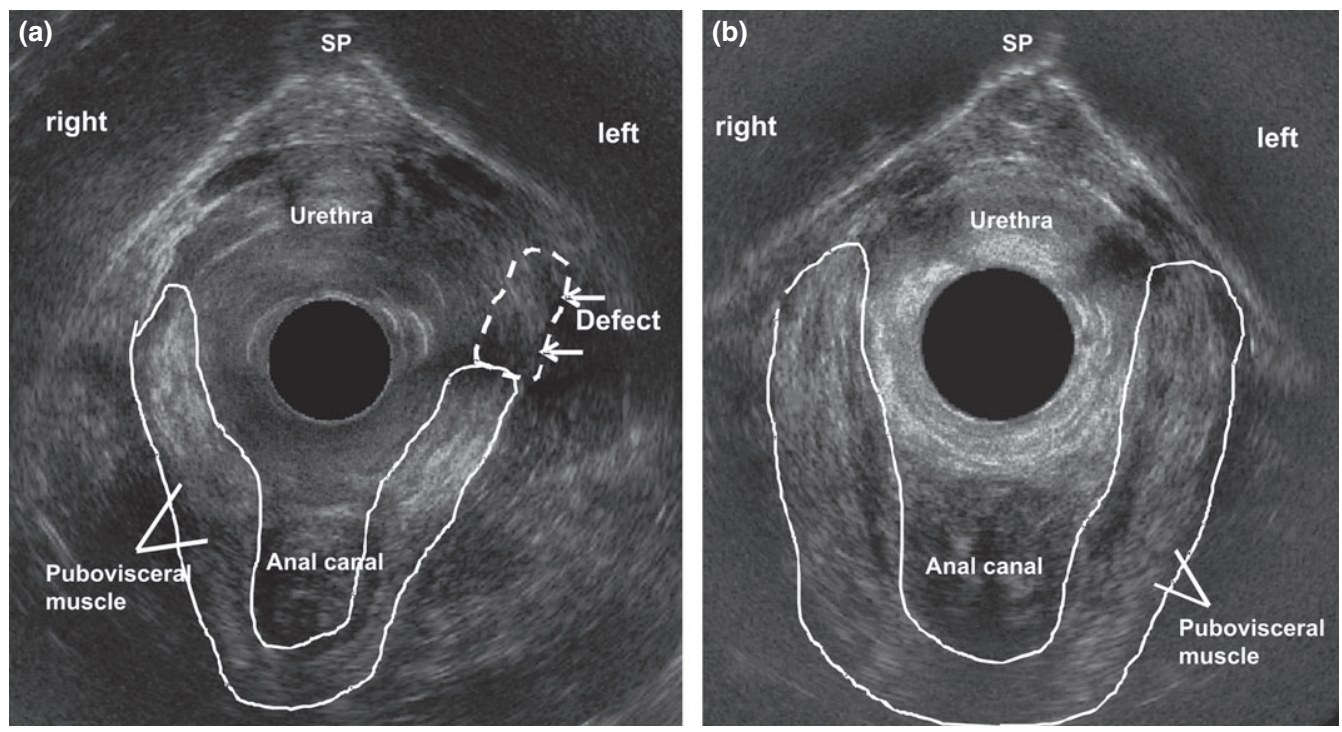

Figure 2 Three-dimensional (3D) endovaginal ultrasonography after vaginal delivery (axial plane). (a) Unilateral pubovisceral muscle defect (left side) (arrows). (b) Intact pubovisceral muscle.

Table 3 Three-dimensional endovaginal and anorectal ultrasound measurements in female patients with previous vaginal delivery and incontinence, with $(n=14)$ or without $(n=38)$ a pubovisceral muscle (PVM) defect, and in asymptomatic nulliparous volunteers $(n=17)$.

\begin{tabular}{|c|c|c|c|c|}
\hline \multirow[b]{2}{*}{ Measurement } & \multicolumn{2}{|l|}{ Patients } & \multirow[b]{2}{*}{ Volunteers $(n=17)$} & \multirow[b]{2}{*}{$P$} \\
\hline & PVM defect $(n=14)$ & PVM intact $(n=38)$ & & \\
\hline \multicolumn{5}{|l|}{ Levator hiatus AP (cm) } \\
\hline At rest & $5.9 \pm 0.58$ & $5.8 \pm 0.56$ & $4.7 \pm 0.41$ & 0.0001 \\
\hline Valsalva manoeuvre & $6.1 \pm 0.81$ & $5.9 \pm 0.67$ & $4.8 \pm 0.47$ & 0.0001 \\
\hline \multicolumn{5}{|l|}{ Levator hiatus LL (cm) } \\
\hline At rest & $4.7 \pm 0.58$ & $3.7 \pm 0.44$ & $3.6 \pm 0.59$ & 0.0001 \\
\hline Valsalva manoeuvre & $5.2 \pm 0.71$ & $3.8 \pm 0.45$ & $3.5 \pm 0.49$ & 0.0001 \\
\hline \multicolumn{5}{|l|}{ Hiatal area $\left(\mathrm{cm}^{2}\right)$} \\
\hline At rest & $19.4 \pm 4.16$ & $17.0 \pm 2.49$ & $12.9 \pm 1.91$ & 0.0001 \\
\hline Valsalva manoeuvre & $22.4 \pm 5.71$ & $18.3 \pm 3.27$ & $12.9 \pm 1.93$ & 0.0001 \\
\hline \multicolumn{5}{|c|}{ Anorectal junction position $(\mathrm{cm})$} \\
\hline At rest & $1.5 \pm 0.96$ & $1.6 \pm 0.82$ & $2.1 \pm 0.72$ & 0.03 \\
\hline Valsalva manoeuvre & $0.5 \pm 0.96$ & $0.9 \pm 0.89$ & $1.5 \pm 0.74$ & 0.03 \\
\hline \multicolumn{5}{|c|}{ Bladder neck position $(\mathrm{cm})$} \\
\hline At rest & $2.3 \pm 0.40$ & $2.2 \pm 0.51$ & $2.8 \pm 0.45$ & 0.0002 \\
\hline Valsalva manoeuvre & $1.6 \pm 0.59$ & $1.6 \pm 0.59$ & $2.3 \pm 0.52$ & 0.0001 \\
\hline
\end{tabular}

Values are given as mean $\pm \mathrm{SD}$. AP, anteroposterior; LL, laterolateral.

\section{Correlation between incontinence scores and 3D ultrasound scores}

There was a significant, positive correlation between incontinence score and ultrasound score $(\rho=0.63$, $P=0.01)$. We found no significant correlations between incontinence scores and the levator hiatal area ( $\rho=0.43, P=0.76$ ) or between ultrasound scores and the levator hiatal area $(\rho=0.24, P=0.08)$. In the patients with a PVM defect, there was a significant correlation between the defect volume and the levator hiatal area $(\rho=0.61, P=0.02)$.

\section{Interobserver variability}

As shown in Table 4, the intraclass correlation coefficients for evaluations by the two blinded surgeons in the sample of 20 participants (including patients with 

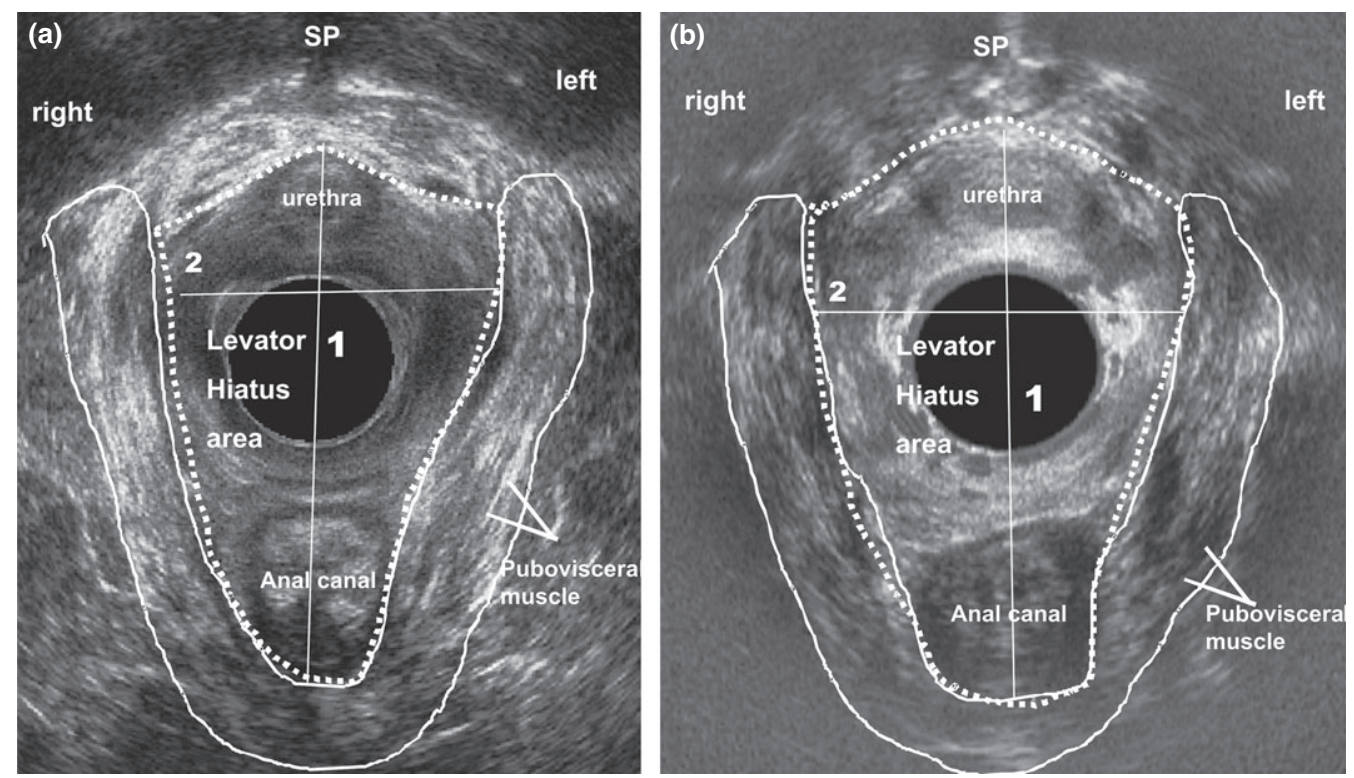

Figure 3 Three-dimensional (3D) endovaginal ultrasonography in (a) a nulliparous patient and (b) a patient with previous vaginal delivery. Measurements of the following biometric indices of the levator hiatus were made: anteroposterior diameter (1); and laterolateral diameter and area (dotted line) (2).
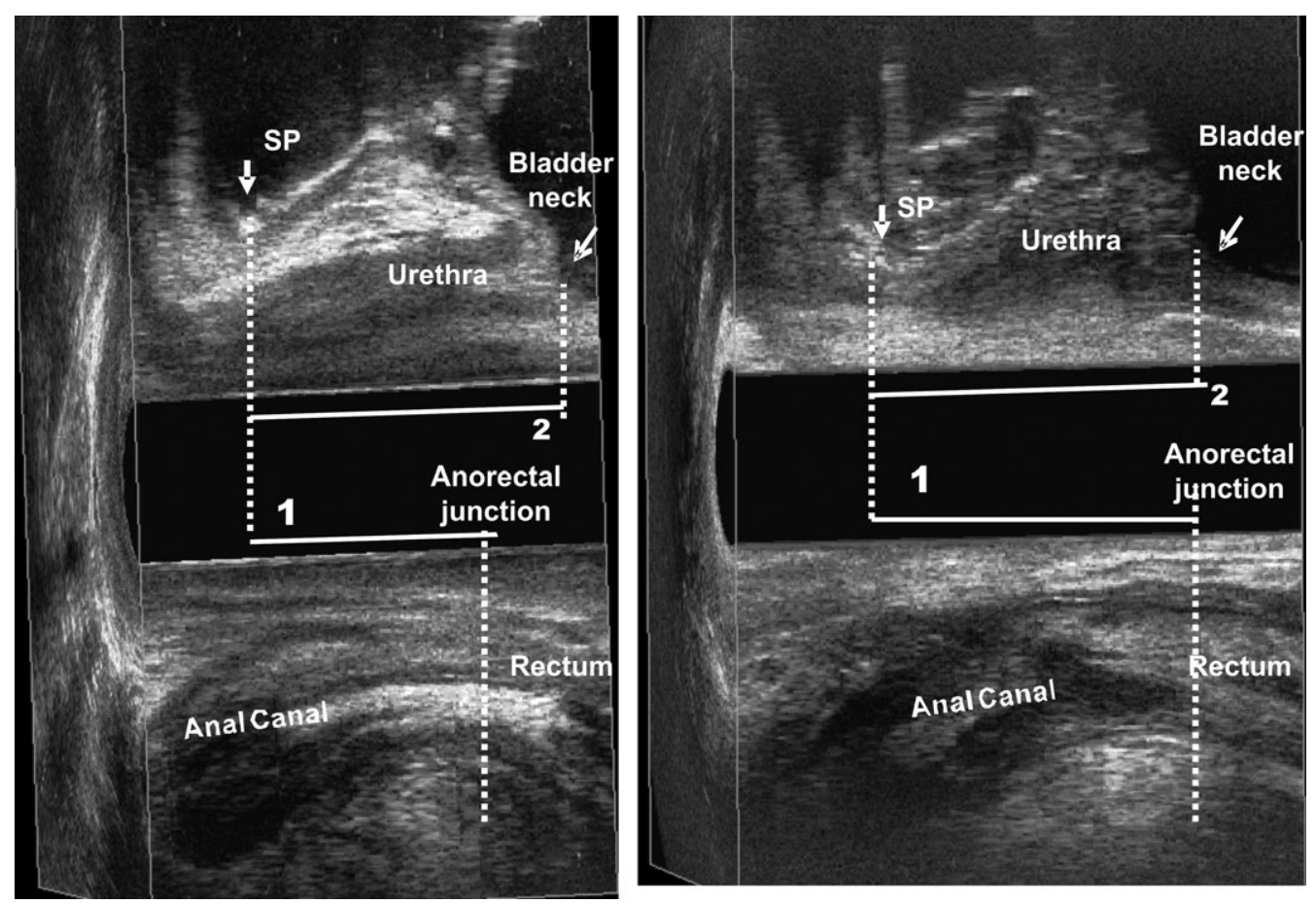

Figure 4 Three-dimensional (3D) endovaginal ultrasound. Measurement of the anorectal junction position (line 1) and of the bladder neck position (line 2) in (a) a nulliparous patient and (b) a patient with previous vaginal delivery.

faecal incontinence symptoms and asymptomatic volunteers) indicated good interobserver agreement for the measurement of laterolateral diameter of the levator hiatal and very good agreement for all other measurements.

\section{Discussion}

Obstetric trauma is a common cause of mechanical injury and/or denervation of the anal sphincter, and the development of faecal incontinence may be associated 
Table 4 Intraclass correlation coefficients for anatomic and functional measurements of the pelvic floor on three-dimensional (3D) endovaginal ultrasonography (two observers) in incontinent women with previous vaginal delivery and in nulliparous volunteers $(n=17)$.

\begin{tabular}{|c|c|c|c|c|}
\hline & \multicolumn{2}{|l|}{ At rest } & \multicolumn{2}{|c|}{ Valsalva } \\
\hline & ICC & $95 \% \mathrm{CI}$ & ICC & $95 \% \mathrm{CI}$ \\
\hline Levator hiatus AP (cm) & 0.936 & $(0.058-0.987)$ & 0.928 & $(0.796-0.972)$ \\
\hline Levator hiatus LL (cm) & 0.923 & $(0.764-0.975)$ & 0.774 & $(0.415-0.913)$ \\
\hline Hiatal area $\left(\mathrm{cm}^{2}\right)$ & 0.951 & $(0.60-0.99)$ & 0.918 & $(0.799-0.963)$ \\
\hline Anorectal junction position $(\mathrm{cm})$ & 0.932 & $(0.787-0.978)$ & 0.857 & $(0.773-0.885)$ \\
\hline Bladder neck position $(\mathrm{cm})$ & 0.960 & $(0.877-0.987)$ & 0.811 & $(0.873-0.932)$ \\
\hline
\end{tabular}

Strength of agreement was interpreted according to the Altman classification system, as follows: $<0.20$, poor; $0.21-0.40$, fair; 0.41 -0.60 , moderate; 0.61-0.80, good; 0.81-1.00, very good. AP, anteroposterior; ICC, intraclass correlation coefficient; LL, laterolateral; PVM, pubovisceral muscle.

with various other risk factors in women with no detectable sphincter defect $[6,7,21]$. Furthermore, women with an occult sphincter defect may develop late-onset incontinence symptoms $[22,23]$. Few data were previously available regarding the relationship between PVM damage and faecal incontinence. We therefore used 3D endovaginal and anorectal ultrasonography to construct an ultrasound score based on defects of the PVM and EAS/IAS. In the present prospective study in women with faecal incontinence and previous vaginal delivery, severity of incontinence was related to the presence and extent of PVM defects as well as to anal sphincter damage.

Our results differ from those of previous studies, which used different methods and were performed in different populations. Chantarasorn et al. [15] retrospectively reviewed records of women who were treated for pelvic floor dysfunction at a tertiary urogynaecological clinic and found no association between the presence of incontinence symptoms (faecal urgency, soiling, faecal incontinence and flatus incontinence) and avulsion of the puborectalis muscles. In a retrospective study of women with pelvic organ prolapse or unexplained symptoms of pelvic floor dysfunction, reported on a quality-of-life questionnaire, Lammers et al. [16] found that major PVM avulsion identified on MRI was positively correlated with pelvic organ prolapse quantification, but not with symptoms of faecal incontinence or obstructed defaecation.

Studies show a wide variation in the incidence of PVM injuries after vaginal delivery, as diagnosed by MRI and ultrasound examination $[1,3,11,12]$. We found that $27 \%$ of incontinent women with previous vaginal delivery had a PVM defect, $71 \%$ of which were unilateral. Lammers et al. [16] found high damage rates in their study population - 44\% were diagnosed with major and $26 \%$ with minor pubovisceral avulsions. Other studies found an increase in hiatal size in women who delivered vaginally, with and without avulsion of the PVM $[4,14,24]$. This agrees with our findings of an increase in the area of the levator hiatus from the measurement at rest to that during the Valsalva maneouvre in patients with vaginal delivery compared with nulliparous volunteers, with a greater increase in those with a PVM defect. We also demonstrated a correlation between the volume of the PVM defect and the area of the levator hiatus. These abnormalities in the PVM and hiatal dimensions are associated with pelvic organ prolapse $[13,14]$ and may impair faecal continence, which, along with other damage, could increase the severity of faecal incontinence symptoms. To date, few data are available regarding the relationship between PVM defects and severity of faecal incontinence symptoms.

We also included a group of asymptomatic nulliparous women for comparison with incontinent patients without a PVM defect to study the effect of vaginal delivery on hiatal dimensions. The biometric indices of the levator hiatus were significantly larger in the patients with vaginal delivery, which was consistent with reports in the literature $[4,14,24]$. We also found that the position of the anorectal junction and the bladder neck was lower in patients with previous vaginal delivery than in nulliparous women. In a previous study [17], in which we used 3D endovaginal ultrasonography to measure pelvic floor anatomy and to determine anorectal junction and bladder neck position in female volunteers, the results were similar to those of the current study.

MRI $[1,16]$ and ultrasonography $[2-4,14,15]$ have been used to visualize PVM defects and to evaluate hiatal dimensions with high spatial resolution. In the present study, the PVM defect was identified using an endovaginal approach and a $12-\mathrm{MHz}$ rotating trans- 
ducer with two crystals (axial and longitudinal) on the extremity, producing a merged 3D cube image recorded in real time for subsequent analysis. Automatic acquisition results in a volume image that can be freely manipulated in all planes and allows visualization of the anatomic structures simultaneously after image processing. We also measured the volume of the defect. These findings are the first detailed evaluation of women with previous vaginal delivery using this technique. Santoro et al. [25] evaluated pelvic floor anatomy and measured biometric indices using the same technique, but in nulliparous female volunteers. All measurements were obtained without any interference from probe movement. The results showed very good and good interobserver variability because of the simplicity of measurements of length, as previously described in the literature $[17,25]$.

Other studies $[13,14]$ have found a strong relationship between prolapse and the occurrence of major levator ani defects. Our study was limited in this respect because quantification of pelvic organ prolapse [26] could not be performed to identify dysfunction in all compartments. We also could not collect data on delivery, performance of an episiotomy, use of forceps or vacuum extraction, vaginal assistance in delivery and birthweight, so we were unable to investigate whether these factors correlated to the presence and extent of the defect. Further studies should evaluate dysfunctions in each compartment, with specialists using specific systems to identify risk factors for dysfunctions in all compartments in women seen before and after their first delivery.

Using 3D endovaginal ultrasonography, this study demonstrated PVM defects in $27 \%$ of women with faecal incontinence who had undergone vaginal delivery. Severity of faecal incontinence is related to the overall extent of damage, as determined using a 3D endovaginal and anorectal ultrasound score, including the anal sphincters and PVM defects. Additionally, vaginal delivery results in enlargement of the levator hiatus and in a lower position of the anorectal junction and bladder neck compared with nulliparous women. Although no conclusions regarding causality can be drawn from a correlational study, it may be important to consider potential damage to the PVM, in addition to sphincter defects, when evaluating women with incontinence after vaginal delivery. Complete diagnostic evaluation of defects in the anal sphincter and PVM should become part of the routine pretreatment assessment of patients with faecal incontinence in order to show the relationship between the presence of PVM damage and the results of treatment.

\section{Funding}

No funding received.

\section{Conflicts of interest}

The authors have no potential conflicts of interest.

\section{Author contributions}

S. Murad-Regadas- contributions to the conception and design, writing the manuscript. GO Fernandes; I Dealcanfreitas; JJR Pereira; FSP Regadas Filho acquisition of the data, data analysis, and interpretation. FSP Regadas, LV Rodrigues -revised the manuscript critically for important intellectual content. All authors have given final approval of the version to be published.

\section{References}

I DeLancey JO, Kearney R, Chou Q, Speights S, Binno S. The appearance of levator ani muscle abnormalities in magnetic resonance images after vaginal delivery. Obstet Gynecol 2003; 101: 46-53.

2 Dietz HP, Lanzarone V. Levator trauma after vaginal delivery. Obstet Gynecol 2005; 106: 707-12.

3 Dietz HP, Steensma AB. The prevalence of major abnormalities of the levator ani in urogynaecological patients. BJOG 2006; 113: 225-30.

4 Shek KL, Dietz HP. The effect of childbirth on hiatal dimensions. Obstet Gynecol 2009; 113: 1272-8.

5 Law PJ, Kamm MA, Bartram CI. Anal endosonography in the investigation of faecal incontinence. Br J Surg 1991; 78: $312-4$.

6 Deen KI, Kumar D, Williams JG et al. The prevalence of anal sphincter defects in faecal incontinence: a prospective endosonic study. Gut 1993; 34: 685-8.

7 Sultan AH, Kamm MA, Talbot IC et al. Anal endosonography for identifying external sphincter defects confirmed histologically. Br J Surg 1994; 81: 463-5.

8 Williams AB, Bartram CI, Halligan S et al. Anal sphincter damage after vaginal delivery using three-dimensional endosonography. Obstet Gynecol 2001; 97: 770-5.

9 Martínez Hernández Magro P, Villanueva Sáenz E, Jaime Zavala M, Sandoval Munro RD, Rocha Ramírez JL. Endoanal sonography in assessment of fecal incontinence following obstetric trauma. Ultrasound Obstet Gynecol 2003; 22: 616-21.

10 DeLancey JO. Anatomy. In: Textbook of Female Urology and Urogynaecology (eds. Cardozo L, Staskin D). London, UK: Isis Medical Media, 2001. pp. 112-24.

11 Kearney R, Miller JM, Ashton-Miller JA, DeLancey JO. Obstetric factors associated with levator ani muscle injury after vaginal birth. Obstet Gynecol 2006; 107: 144-9. 
12 DeLancey JO, Morgan DM, Fenner DE, Kearney Guire, K, Miller, JM, Hussain, H, Umek, W, Hsu, Y, Ashton-Miller, JA. Comparison of levator ani muscle defects and function in women with and without pelvic organ prolapse. Obstet Gynecol 2007; 109: 295-302.

13 Dietz HP, Simpson JM. Levator trauma is associated with pelvic organ prolapse. BJOG 2008; 115: 979-84.

14 Abdool Z, Shek C, Dietz HP. The effect of levator avulsion on hiatal dimensions and function. Am J Obstet Gynecol 2009; 89: 1-5.

15 Chantarasorn V, Shek KL, Dietz HP. Sonographic detection of puborectalis muscle avulsion is not associated with anal incontinence. Aust NZ J Obstet Gynaecol 2011; 51: 130-5.

16 Lammers K, Fütterer JJ, Inthout J et al. Correlating signs and symptoms with pubovisceral muscle avulsions on magnetic resonance imaging. Am J Obstet Gynecol 2013; 208: 148.el-148.e7.

17 Murad-Regadas SM, Bezerra LR, Silveira CR et al. Anatomical and functional characteristics of the pelvic floor in nulliparous women submitted to three-dimensional endovaginal ultrasonography: case control study and evaluation of interobserver agreement. Rev Bras Ginecol Obstet 2013; 35: 123-9.

18 Abrams P, Cardozo L, Fall M et al. The standardization of terminology of lower urinary tract function: report from the standardization sub-committee of the International Continence Society. Urology 2003; 61: 37-49.
19 Jorge JMN, Wexner SD. Etiology and management of fecal incontinence. Dis Colon Rectum 1993; 36: 77-97.

20 Altmann DG. (1991). Practical Statistics for Medical Research. Chapman \& Hall, London.

21 Menees SB, Smith TM, Xu X et al. Factors associated with symptom severity in women presenting with fecal incontinence. Dis Colon Rectum 2013; 56: 97-102.

22 Karoui S, Savoye-Collet C, Leroi AM et al. Prevalence of anal sphincter defects revealed by sonography in 355 incontinent patients and 111 continent patients. AJR Am J Roentgenol 1999; 173: 389-92.

23 Oberwalder M, Dinnewitzer A, Baig MK et al. The association between late-onset fecal incontinence and obstetric anal sphincter defects. Arch Surg 2004; 139: 429-32.

24 Dietz HP, Bhalla R, Chantarasorn V, Shek KL. Avulsion of the puborectalis muscle is associated with asymmetry of the levator hiatus. Ultrasound Obstet Gynecol 2011; 37: 723-6.

25 Santoro GA, Wieczorek AP, Stankiewicz A, Wozniak MM, Bogusiewicz M, Rechbereger T. High-resolution three-dimensional endovaginal ultrasonography in the assessment of pelvic floor anatomy: a preliminary study. Int Urogynecol J 2009; 20: 1213-22.

26 Bump RC, Mattiasson A, Bo K et al. The standardization of terminology of female pelvic organ prolapse and pelvic floor dysfunction. Am J Obstet Gynecol 1996; 175: 10-7. 